\title{
História do ensino superior no Rio Grande do Norte e a desigualdade de acesso
}

\author{
History of higher education in Rio Grande do Norte and the inequality of access \\ Historia de la educación superior en Rio Grande do Norte y la desigualdad de acceso
}

Recebido: 15/09/2021 | Revisado: 18/09/2021 | Aceito: 19/09/2021 | Publicado: 20/09/2021

\author{
Francisca Liliane da Cunha \\ ORCID: https://orcid.org/0000-0002-6318-0577 \\ Universidade Federal do Rio Grande do Norte, Brasil \\ E-mail: lili.anecunha@hotmail.com \\ Kilza Fernanda Moreira de Viveiros \\ ORCID: https://orcid.org/0000-0003-1243-7595 \\ Universidade Federal do Rio Grande do Norte, Brasil \\ E-mail: kilza.fernanda@hotmail.com
}

\begin{abstract}
Resumo
Esse trabalho refere-se a uma pesquisa de Mestrado do Programa de Pós-graduação em Educação desenvolvida na Universidade Federal do Rio Grande do Norte. O estudo tem por objetivo compreender e discutir, o campo do ensino superior no Estado do Rio Grande do Norte e a desigualdade de acesso nos primeiros cursos de bacharelado na área da educação agregados à Universidade do Rio Grande do Norte (URN), no período entre os anos de 1958 a 1968 . Com o objetivo de pesquisar a desigualdade de acesso dos jovens, que concluíam o curso secundário e poderiam prosseguir em sua formação de nível superior a qual este estudo se faz necessário. A Síntese Cronológica da UFRN 1958/2017 (Volume I), nos dá respaldo sobre o contexto sócio histórico da educação e principalmente os sujeitos que ingressavam ao ensino superior neste período. O Repositório Institucional da Universidade Federal do Rio Grande do Norte, foi o recurso recorrido para fornecer dados no desenvolvimento desta pesquisa, que se fundamenta teórico metodologicamente na história cultural, portanto essa investigação será documental e bibliográfica. O estudo acerca da desigualdade de acesso no ensino superior apresenta significados no campo da história da educação.
\end{abstract}

Palavras-chave: Ensino superior; Desigualdade; História da educação; Memória.

\begin{abstract}
This work refers to a research carried out by the Master's Degree Program in Education at the Federal University of Rio Grande do Norte. The study aims to understand and discuss the field of higher education in the State of Rio Grande do Norte and the inequality of access in the first bachelor's degree courses in the area of education added to the University of Rio Grande do Norte (URN), in the period between the years 1958 to 1968 . With the objective of researching the inequality of access of young people, who completed secondary school and could continue their higher education training, which this study is necessary. The Chronological Synthesis of UFRN 1958/2017 (Volume I) gives us support on the socio-historical context of education and especially on the subjects who entered higher education in this period. The Institutional Repository of the Federal University of Rio Grande do Norte, was the resource used to provide data in the development of this research, which is theoretical and methodologically based on cultural history, so this investigation will be documental and bibliographical. The study about inequality of access in higher education has meanings in the field of the history of education.
\end{abstract}

Keywords: Higher education; Inequality; History of education; Memory.

\begin{abstract}
Resumen
Este trabajo se refiere a una investigación realizada por el Programa de Maestría en Educación de la Universidad Federal de Rio Grande do Norte. El estudio tiene como objetivo comprender y discutir el campo de la educación superior en el Estado de Rio Grande do Norte y la desigualdad de acceso en los primeros cursos de licenciatura en el área de educación incorporados a la Universidad de Rio Grande do Norte (URN), en el período comprendido entre los años 1958 a 1968. Con el objetivo de investigar la desigualdad de acceso de los jóvenes, que completaron la educación secundaria y pudieron continuar su formación en educación superior, por lo que este estudio es necesario. La Síntesis Cronológica de la UFRN 1958/2017 (Volumen I) nos brinda apoyo sobre el contexto sociohistórico de la educación y especialmente sobre los sujetos que ingresaron a la educación superior en este período. El Repositorio Institucional de la Universidad Federal de Rio Grande do Norte, fue el recurso utilizado para aportar datos en el desarrollo de esta investigación, la cual se basa teórica y metodológicamente en la historia cultural, por lo que esta investigación será documental y bibliográfica. El estudio sobre la desigualdad de acceso a la educación superior tiene significados en el campo de la historia de la educación.
\end{abstract}

Palabras clave: Educación superior; Desigualdad; Historia de la educación; Memoria. 


\section{Introdução}

O presente artigo consiste em compreender e discutir, o campo do ensino superior no Estado do Rio Grande do Norte e a desigualdade de acesso aos primeiros cursos de bacharelado na área da educação que foram agregados á Universidade do Rio Grande do Norte-URN. Este estudo se propõe a analisar os aspectos sócio históricos e culturais dos processos de acesso e permanência dos sujeitos em trajetória de formação durante o período de 1958 a 1968.

A partir da óptica da história do ensino superior, é necessária a contextualização do nosso objeto de estudo, a fim de que possa conhecer as condições sociohistóricas e culturais em que esses cursos propiciaram o acesso às pessoas menos favorecidas. As investigações científicas já realizadas assinalam que a Faculdade de Filosofia de Natal foi autorizada a funcionar pelo Decreto Federal n ${ }^{\circ}$ 49.573, de 18 de dezembro de 1956, com a criação do Curso de Geografia, História e Letras, que foi reconhecido somente no ano de 1959 pelo Decreto Federal n ${ }^{\circ} 46.868 / 59$.

A instituição pública surge da necessidade da instalação de uma universidade, que tinha como foco principal o espirito de investigação, o gosto pela cultura que se desenvolvem de maneira surpreendente. Os jovens de ambos os sexos, que concluíam o curso secundário, podiam prosseguir em sua formação de nível superior, concorrendo, na constituição de uma elite cultural numerosa, e que, com a disseminação das Universidades Regionais, tinha a importância da descentralização do ensino superior, com capacidade de alcançar a massa enorme de futuros profissionais.

A partir de sua criação, conforme a Lei Estadual no 2.307, de 25 de junho de 1958, sancionada pelo Governador Dinarte de Medeiros Mariz, o espaço educativo passa a ser uma instituição de "ensino superior e de alta pesquisa, com personalidade jurídica dotada de autonomia didática, administrativa, financeira e disciplinar, nos termos da legislação federal", e tem por finalidades, o desenvolvimento a cultura filosófica, científica, literária e artística fundado no respeito à dignidade da pessoa humana e aos seus direitos naturais e essenciais (Melo, 2019).

Não obstantes, as Leis e Decretos governamentais, no ano de 1961, com o Decreto Federal no 50.211, foi aprovado o Estatuto da Universidade Federal do Rio Grande do Norte, a qual se adotou à Lei de Diretrizes e Bases da Educação Nacional (Lei $\mathrm{n}^{\circ}$ 4.024, de 20 de dezembro de (1961) e, foi de extrema importância na integração das Unidades Incorporadas e as Unidades Agregadas.

Norteando o objeto de pesquisa para o qual se direciona esse estudo, apontarei o percurso praticado enquanto pesquisadora, por meio de vestígios documentais encontrados, cujo instrumento de análises nos foram possíveis.

A trajetória da pesquisa segue-se a partir de estudos anteriores, a qual se propôs a investigar a educação, pobreza e desigualdade social em diversos níveis de escolaridade no Estado do Rio Grande do Norte, no grupo de estudo sobre Educação, pobreza e desigualdade social entre os anos de 2017/2019 da base de pesquisa, sob orientação da professora $\operatorname{Dr}^{\mathrm{a}}$ Kilza Fernanda Moreira de Viveiros, a qual resultou artigos publicados em livro, Educação: Base para formação cidadã, cujo tema do artigo foi: Educação e Pobreza: Trajetória e Desafios (Cunha \& Viveiros, 2020) e no evento da Semana Integração de Estudantes da Ead da Universidade Aberta do Brasil - UAB, na qualidade de conferencista com estudantes do Ensino Superior dos cursos de graduação em Computação, Matemática, Física e Química dos Polos de São Gonçalo do Amarante, Angicos e Pau dos Ferros da Universidade Federal Rural do Semi-Árido - UFERSA. Cujos temas foram: Perspectiva da Carreira docente pós-pandemia. (Cunha \& Silva, 2020). A contar dos documentos analisados para estudos, percebemos a presença de citações referentes ao ensino superior e a desigualdade de acesso. Entre os anos de 1958 e 1968, a partir dessas observações nos dispomos adentrar nas análises desses escritos a fim de conhecer a história desses primeiros cursos de bacharelado em educação e os sujeitos que iniciaram esse processo de acesso dentroda instituição de ensino superior.

Ao escolhermos explorar este objeto de pesquisa e suas possibilidades históricas, iniciamos o levantamento bibliográfico, a fim de contemplar um diagnóstico que nos auxiliasse nas referências, assim como estudos já realizados a partir 
da temática. Dessa forma, utilizaremos outras fontes de acesso de jovens brasileiros ao ensino superior, nas bases de dados do Google acadêmico, da Scielo, a Síntese cronológica da UFRN-Volume I e os periódicos da Capes.

Ao realizarmos essas buscas, conseguimos os resultados obtidos, que nos mostraram o quantitativo de estudos realizados, sendo possível perceber o objeto de uma maneira bem sucinta, apenas na Síntese Cronológica da UFRN (1958/2017) Volume I. A qual o autor traça um panorama a respeito dos primeiros cursos de ensino superior, os estudantes que ingressaram nesses cursos, a fundação da Universidade do Rio Grande do Norte-URN (1958), sua federalização (1960), Decreto no 62.091, de 09 de janeiro de 1968, reestruturou a instituição com o Novo Estatuto da Universidade Federal do Rio Grande do Norte-UFRN, a criação dos institutos de cada curso; dentre outros. Porém, tomo como referência no alicerce deste estudo.

Logo, compreendemos a necessidade de nos debruçarmos sobre a dimensão histórica do ensino superior no Estado do Rio Grande do Norte e, desse modo, conduzimos as leituras na base de pesquisa da Educação, Pobreza e Desigualdade Social 2017/2019, tendo em vista que, a história e as mudanças na vida humana são sempre impulsionadas a partir de sua base material, isto é, das condições objetivas e concretas (Barros, 2013, p. 32).

O então estudo resultou de uma exposição relacionada à temática da Desigualdade Social e seus Desdobramentos na Educação, na Disciplina de Fundamentos Sócio Filosófico da Educação a estudantes do ensino superior, ao qual exploramos e discutimos o tema relacionando a desigualdade da educação superior seus programas e legislações destinadas a essa temática, partindo dessas observações e inquietações, nos dispomos à análise desses estudos a fim de conhecer com mais profundidade a histórias desses jovens que ingressaram na educação superior.

Assim, a pesquisa em questão teve seu inicio no processo de formação docente na coordenação de curso de Pósgraduação de formação inicial e continuada no centro de educação especificamente no curso de especialização em Educação, Pobreza e Desigualdade Social, como também como aluna especial do programa de pós-graduação da linha de pesquisa em Educação Socio histórica e Filosófica. Ao iniciar lapidando-se a cada etapa construída, tendo em vista que, segundo Barros (2013), "as transformações dão-se a partir do desenvolvimento de "contradições", isto é, de inúmeras forças sociais e produtivas". Nesse sentido, as observações e os estudos nos possibilitaram encontros que só ampliaram o desejo intenso pelo objeto.

Diante dessa trajetória, ressaltamos que a história da educação é um campo de saber que o historiador dedica-se a estudar a própria história, contudo, a historiografia busca a verdade acima de tudo, como uma atitude moral, que se desdobra sobre si mesmo como discurso de fontes de múltiplas maneiras (Barros, 2011).

Para isto, o então projeto de dissertação me proporciona enquanto pesquisadora, a oportunidade de prosseguir na reconstrução, através de indícios históricos, e do trajeto até então pouco rememorada do ensino superior, a formulação de profissionais para área de educação e a desigualdade de acesso a esses cursos na instituição pública de ensino.

Diante disso, compreendemos que o ensino secundário tinha como finalidade o acesso ao ensino superior, mas que estavam restritas somente às elites, porém havia uma grande visibilidade com a figura dos excedentes, ou seja, jovens que obtinham a nota mínima de aprovação nos exames vestibulares, mais que não podiam ingressar no ensino superior por falta de vagas, desse modo, reforçam a necessidade de investigação e análise.

Ressaltamos que a busca por explorar o percurso desses alunos na educação superior e o acesso da desigualdade social nas instituições universitárias, ocorreu por mera curiosidade, mas, para entender os movimentos de uma sociedade, e de um determina do grupo social, de uma determinada época que iniciou toda trajetória no estado do Rio Grande do Norte.

Todavia, não há como estudar uma instituição sem voltarmos o olhar para seus sujeitos, suas práticas, suas perspectivas formativas e sociais, tendo em vista que, conhecer uma determinada realidade requer do pesquisador uma aguçada 
percepção do seu entorno, concebendo para tal, uma análise de tudo que está inserido e contribui para a formação daquele recorte social.

\section{Metodologia}

A escolha do tema desta pesquisa compreende uma articulação documental bibliográfica com intenção de discutir de forma exploratória uma temática ainda pouco discutida na academia. Nesse contexto adotaremos os pressupostos da Nova História e História Cultural e, para isto, a abordagem dos aspectos teóricos historiográficos, a partir de fontes específicas do Materialismo Histórico e Dialético, a qual será possível à compreensão e contradições que se estabelecem socialmente (Barros, 2013). Para nos aprofundarmos no objeto de estudo, arremessaremos mão de uma análise articulada desde uma pesquisa historiográfica considerada por (Arostegui, 2006), quando destaca que - Não se pode fazer história se não se dispõe de uma técnica superior, que é uma teoria geral das realidades humanas.

Dessa maneira, supomos enquanto objeto de pesquisa a perspectiva exploratória, considerando uma intensa varredura de documentos com os quais se fará a possível compreensão em acervos físicos e virtuais disponibilizados pelos repositórios institucionais daUniversidade Federal do Rio Grande do Norte - UFRN (1958-2017/Volume 1), e também do Repositório de História e Memória da Educação (RHISME), LAHMED, LABIM da UFRN.

Para fundamentar o processo de reconstrução histórica do objeto, capturaremos por fontes os arquivos de revistas e publicações oficiais, contudo enfatizar o que diz (Bloch, 2001, p.82) -Reunir os documentos que estima necessários é uma das tarefas mais difíceis do historiador.

Com o intuito de melhor articulação dos resultados das análises e a delimitação das referências teóricas, subsequentemente analisaremos os conceitos de espaço, cultura e educação na perspectiva de (Bourdieu, 2008), práticas e lugar (Certeau, 1982; 1998), história e tempo (Bloch, 2001) documento e memória segundo (Le Goff, 1996), desse modo cada analisaremos sistematicamente cada categoria pertencente aos aportes teóricos apontados.

Desse modo, a metodologia prevê a compreensão que a pesquisa em história se constrói com métodos de investigação, análise e escrita, a partir de possibilidades que o pesquisador se dispõe a construir seu objeto e as oportunidades que os vestígios e fontes lhes concedam.

\section{Resultados e Discussão}

Este projeto se insere no campo de pesquisa da base de estudos sociohistóricos e filosóficos, ao qual tomaremos como base norteadora uma fundamentação teórica a partir de Saviani (2011), A Expansão do Ensino Superior no Brasil, A Educação Brasileira e a Pedagogia Histórico-Crítica, podemos definir a História da Educação com a qual contemplaremos a organização e a concretização deste estudo.

Esse campo de pesquisa da história da educação nos permite discutir e explorar a reconstrução de tempos, espaço e sociedade, seja através de seus escritos, ou até mesmo das suas ações no contexto social. - Ser histórico é -ser no tempo [,,,] é uma consequência uma das várias essenciais, se não a absolutamente essencial entre as que integram a definição da realidade histórica. (Arostegui, 2006, p. 271).

Nesse sentido, entendemos o tempo da história e seus movimentos construtores na educação superior no estado do Rio Grande do Norte e a desigualdade de acesso (Arroyo, 2021) enquanto a pobreza for pensada como questão moral, os pobres continuaram sendo pensados para moralizá-lo (as).

Desse modo, a Universidade Federal do Rio Grande do Norte - UFRN surge ao final da década 1950, mais precisamente em 1958, tendo como missão - Educar, produzir e disseminar o saber universal, preservar e difundir as artes e a 
cultura, e contribuir para o desenvolvimento humano, comprometendo-se com a justiça social, sustentabilidade sócio ambiental, a democracia e cidadania (UFRN, 2012. P. 9).

Da mesma forma que os jovens das camadas superiores se distinguem por diferenças que podem estar ligadas a diferenças de condição social, também os filhos das classes populares que chegam até o ensino superior parecem pertencer a famílias que diferem da média de sua categoria, [...] poder-se-ia esperar encontrar, numa população de estudantes investigada, a mesma relação (40/1) entre o número médio de indivíduos com estudos das camadas superiores. (Bourdieu, 2007, p. 43-44).

Contudo, não há como estudar em uma instituição pública de ensino superior sem atentar para seus sujeitos, isso requer do pesquisador um olhar atento ao seu entorno, onde os detalhes não são nunca o que são, cada lembrança os altera, "as análises cientificam contemporânea que se inscrevem memória nos seus quadros sociais” (Certeau, 1998.p.165)

Para acolher populações de alunos cada vez mais numerosos e mais desprovidos do ponto de vista cultural e que deixaram de ter alguma coisa ver com o liceu, tal como este se perpetuou até os anos 50, por outro, os estabelecimentos altamente preservados, onde, os alunos oriundos de boas famílias, podem seguir, ainda hoje, uma trajetória escolar que não é radicalmente diferente daquela que foi seguidapelos pais e avós. (Bourdieu, 2007, p. 19).

Essa realidade é confirmada por Pochmann (2014, p.14) ao afirmar que, a desigualdade pode ser medida de oportunidades, desigualdade de resultados. O acesso universalizado, a qualidade da educação é uma coisa dramática, dessa forma, reproduz a desigualdade, pois o conceito de pobreza em si é um componente da própria condição da exclusão social.

Procuraremos, nessa busca, investigar as fontes documentais e prezaremos pelos seus registrados, que possamos nos permitir o conhecer sobre os cursos de graduação de nível superior para sociabilizar a desigualdade social dos egressos dentro da instituição universitária.

\section{Considerações Finais}

A inserção dos jovens de ambos os sexos dentro do campo do ensino superior no Estado do Rio Grande do Norte vem nos proporcionando um estudo que nos faz analisar os aspectos sócios históricos e culturais, de acesso e permanência na trajetória de formação durante o período de 1958 a 1968.

Quando se aborda detalhadamente o acesso a educação do ensino superior, percebe-se que os jovens que concluíam o ensino secundário, podiam prosseguir em sua formação de nível superior, concorrendo, na constituição de uma elite cultural numerosa, percebe-se que com o desenvolvimento do povo brasileiro, expandiram-se demandas por vagas no ensino superior, apesar de que, os jovens realizavam exames vestibulares a qual obtinham notas mínimas de aprovação, mas não podiam ingressar a essa modalidade por falta de vagas.

Evidentemente, no tocante à educação, a imposição do certificado de ensino secundário, era por meio de definir o controle aditivo às escolas superiores, além de proporcionar um rigoroso processo de exame vestibular, a qual incidia a candidatos que tivessem o mínimo de conhecimento em um curso superior. Para isto, o então projeto de dissertação consentirá a oportunidade de prosseguir na reconstrução, no trajeto até em pouco tempo rememorada do ensino superior.

Ainda há muito a se discutir sobre a temática na área de história da educação do ensino superior e a desigualdade de acesso a esses cursos na instituição pública de ensino, compreendemos que o ensino secundário tinha como finalidade o acesso ao ensino superior, mas que por falta de vagas não podiam ingressar, desse modo, reforçam a necessidade de investigação e análise. Também, ressaltamos a busca por explorar o percurso desses alunos na educação superior e o acesso da desigualdade social nas instituições universitárias. 


\section{Referências}

Almeida Neto, M. (2013). Desigualdades educacionais \& pobreza In: Fahel, M. et. al. (orgs.). Editora PUC Minas.

Araújo, A. T. S., Stamatto, M. I. S., \& Medeiros Neta, O. M. (2019). A Fundação da Universidade do Rio Grande do Norte: Entre Histórias e Memórias. Revista Cenas Educacionais, Caetité 2(Especial), 18-38. https://revistas.uneb.br/index.php/cenaseducacionais/article/view/7364/4792

Aróstegui, J. (2006). A pesquisa histórica: teoria e método. Edusc.

Arroyo, M. G. (2015ª). Módulo Introdutório: Pobreza e Educação. In: Brasil. Secretaria de Educação Continuada, Alfabetização, Diversidade e Inclusão SECADI. Ministério da Educação. Brasilia. http://egpbf.mec.gov.br/

Barros, José D'assunção. (2011). Teoria da História.: Editora Vozes.

Barros, J. D. (2013). Teoria da História. Ed. Vozes.

Bourdieu, P. (2007). Escritos da Educação. (9a ed.) Vozes.

Bourdieu, P (1997). A miséria do mundo. Petrópolis: vozes.

Bloch, M. L. B, (2001). Apologia da história, ou, O ofício de historiador / M. Bloch; prefácio, J.L. Goff; apresentação à edição brasileira, L. M. Schwarcz; tradução, A. Telles. Jorge Zahar Ed.

Certeau, M. (1982). A escrita da história. (M. L. Menezes, Trad.). *Revisão Técnica [De] Arno Vogel. Forense Universitária.

Certeau. M. (1998). A invenção do cotidiano. (3a ed.), Vozes.

Cunha, L. A. (1986). A universidade Temporã. (2a ed.), Alves.

Cunha, F. L. \& Viveiros, K. F. M. (2020). Educação: base para formação cidadã. Terceirize.

Decreto - Lei estadual n 2.307 , de 25 de junho de 1958. Cria a Universidade Estadual do RioGrande do Norte e dá outras providências. Diário Oficial do Rio Grande do Norte, Natal. https://www2.camara.leg.br/legin/fed/decret/1960-1969/decreto-50211-28-janeiro-1961-389864-estatuto-pe.doc

Geertz, C. (1997). O saber local: novos ensaios em antropologia interpretativa. Tradução de Vera Mello Joscelyne. Vozes.

Ginzburg, C. (1983). Señales: Raíces de un Paradigma Indiciario. In Gargani, A. (org.) Crisis de la Razón. México.

Guerra, A., Pochmann, M. S., \& Silva. R. A. (2014). Atlas da exclusão social no Brasil: dez anos depois, Cortez.

Le Goff, J. (1996). A História e Memória. (4a ed.), Ed. Unicamp.

Le Goff, J. (1990). A História Nova. (E. Brandão, Trad.). Martins Fontes.

Melo, V. \& Calado, C. (2019). Síntese Cronológica da UFRN 1958/2017. Edufrn, 1 v.

Menezes, A. B. N. T., Paiva, M. M., \& Stamatto, M. I. S. (Org.) (2016). Práticas educativas: educação escolar e não-escolar. Mercado de Letras. 246 p. (Educação geral, superior, formação e continuadado educador).

Nunes, C. (2005). História Cultural e História da Educação, uma leitura de Clarice Nunes, (Entrevistadores: M. M. Araújo, M. P. Oliveira \& J. W. Germano). Revista Educação em Questão, Natal, 22(8), 253-263.

Saviani, D. (1983). 1944 - Educação Brasileira: estrutura e sistema. (5a ed.), Saraiva.

Saviani, D. (2011). Pedagogia histórico - crítica: primeiras aproximações. (11a ed.), Autores Associados. (Coleção educação contemporânea).

Teixeira, A. (1989). O ensino Superior no Brasil - Análise e Interpretação de sua Evolução até 1969. Fundação Getúlio Vargas.

Viveiros, K. F. M. et al. (2018). Escola, Pobreza e Cidadania. (Vol. II). Série.Educação, Pobreza e Desigualdade Social - UFRN. Ideia.

Yannoulas, S. C., Assis, S. G., \& Ferreira, K. M. (2012). Educação e Pobreza: limiares de um campo em (re) definição. Revista Brasileira de Educação, $17(50)$. 